\title{
Impact of Educational Computer Games on Academic Motivation and Stress Reduction in Students
}

\author{
Narges Mirani Sergzi ${ }^{1}$, Mohadeseh Ordoni ${ }^{2}$, Mohammad Sadegh Besharatnia ${ }^{3}$, \\ Mohammad Reza Dastamooz ${ }^{1}$, Mohammad Javad Heydari Abravan ${ }^{4, *}$ \\ ${ }^{1}$ Educational Management, Faculty of Psychology and Educational Sciences, Shiraz University, Shiraz, Iran \\ ${ }^{2}$ Educational Psychology, Faculty of Psychology and Educational Sciences, Sistan and Baluchestan University, Zahedan, Iran \\ ${ }^{3}$ Curriculum Studies, Faculty of Psychology and Educational Sciences, Shiraz University, Shiraz, Iran \\ ${ }^{4}$ Department of Business Management, Faculty of Management, Imam Reza International University, Mashhad, Iran
}

Email address:

M.heydari@gmail.com@gmail.com(M. J.H. Abravan)

${ }^{*}$ Corresponding author

\section{To cite this article:}

Narges Mirani Sergzi, Mohadeseh Ordoni, Mohammad Sadegh Besharatnia, Mohammad Reza Dastamooz, Mohhamad Javad Heydari Abravan. Impact of Educational Computer Games on Academic Motivation and Stress Reduction in Students. International Journal of Elementary Education. Vol. 9, No. 3, 2020, pp. 71-76. doi: 10.11648/j.ijeedu.20200903.13

Received: August 8, 2020; Accepted: August 27, 2020; Published: September 21, 2020

\begin{abstract}
Life stresses, a decisive role in mental and physical health with strength and especially with the mental injuries and communities of some with you. Identifying student stress is the basic basis for designing and developing pre-existing programs. This study aimed to investigate the impact of educational computer games on academic motivation and stress reduction in high school students. This is applied research with a quasi-experimental design. For this purpose, 80 high school students, From the age of 14 to 17 years, in the 4th district of Shiraz city in the academic year of 2019-20 were assigned into two experimental and control groups via a convenient sampling method. The experimental group received fifteen training sessions of 45 minutes each for two months. The instruments used for this study were Test of Motivation Achievement by Hermans (1977) and Beck Anxiety Inventory (BAI) (1988). Data analysis was performed using SPSS software. The results of data analysis showed that computer educational games are effective in motivating (33.9) and lowering stress (37.4) among the students, respectively. Implications for practice. Computer games, due to their attractiveness, simultaneous use of different senses and interaction with the user, provide an attractive and enjoyable environment for the user, so that many users play these types of games spontaneously and with great enthusiasm.
\end{abstract}

Keywords: Computer Games, Academic Motivation, Stress Reduction, Educational Games

\section{Introduction}

Developments made in hardware and software domains were so significant which are beyond expression and occupied a special place in schools and homes. In the late 1970s, with the advent of Apple computers, the schools were able to afford to buy computers. Then, the advent of Macintosh computers in 1984, which used visual and mouse interfaces, made computers easily accessible to children and adults. In 1985, IBM entered the PC market with the use of a Visual Intermediate System known as Microsoft Windows. Over the next years, with the emergence of very powerful microprocessors, computer-based learning was made possible through computer-controlled multimedia applications, and as a result, many educational and scientific resources were made available with the emergence of the World Wide Web [1].Throughout history, philosophers and theorists - including Plato, Vygotsky, Piaget, and Rousseau - have expressed the positive role of play in a child's development and education, and DLGs are a modern tool to efficiently integrate play into 21st-century classrooms [2].

With the increasing use of computer technology especially since the last decade, the use of computerbased instruction methods has become more common. In today's information society, where people use information in any area possible from economy as consumers to education as learners or 
instructors, the tools providing information have also become incredibly important [3].

The use of computer games enables students to engage in the active process of learning. In fact, some games and activities promote children's learning more than any other books available. There are many reasons to use games as a teaching method in the educational settings including encouraging students, adapting to individual student learning styles, promoting active learning during play. As active participants, children make decisions, solve problems and respond to their decisions [4]. Similarly, as one of the computer game theorists, Sutton-Smith [5] holds that the game provides users with a mechanism that helps them regulate and direct their cognitive control and mental health challenges. Because of their objective thinking, young students need to use approaches with a more objective nature. In this regard, computer games are among the tools that provide the students with opportunities to learn their lessons in an objective, engaging and entertaining way. The new and emerging technologies are capable to facilitate learning, increase their speed, as well as reduce learning time and create more favorable conditions for learning [6]. Despite all its amazements, beauties, and advances, the world where we live in is full of fear and anxiety. Stress is an inevitable aspect of life and everyone experiences it. while stress can be motivating, when self-worth is tied to outcomes, failure can become devastating. Poor testing history can create a negative mindset surrounding tests and influence future outcomes. Finally, lack of preparation can leave individuals feeling anxious and overwhelmed [7].

Students face various stressful conditions from every day to major life events Stress is a general experience in all human lives [8]. For the last five decades, stress and its coping strategies are among the first issues empirically explored. It is important to say that enduring mental stress and the inability to cope with it underlie the significant proportion of physical and mental distress. Research has shown that a higher proportion of people are exposed to stress and negative emotion if too little attention is given to the well-being and establishing friendly relationships in organization management [9]. The term Mover is another stress-related variable suggested in motivation progress research [10]. Psychologists defined motivation as an internal process that directs and maintains behavior over time [11]. Academic motivation is an important aspect of teaching and learning; it refers to the willingness, needs, and factors that influence a person to attend school and obtain a degree [12]. It also encompasses the needs and factors that make a person attend the educational environment and obtain academic ranks [13]. Numerous factors contribute to the students' performance, motivation and academic achievements such as intelligence, aptitude, mental abilities, personal variables, self-perception and adaptation and motivational and cognitive variables. Motivational and cognitive variables are among the most important variables affecting academic performance, which can be manipulated by the teacher. Students need cognitive and motivational skills to perform well in school and accomplish their tasks more effectively. As a critical motivational variable, the classroom environment plays a vital and powerful role in students' academic, psychological, and behavioral performance [14]. In this respect, Horner, an American psychologist, put forward the "Fear of Success" theory, postulated that societal expectations contribute to the females' motivational systems and teachers, directly or indirectly, are forced to treat girls and boys differently. She concluded that different motivational patterns may be the result of social conditioning. She also believes that lower levels of achievement are associated with unpleasant consequences. Fear of success may arise because students fear that their relationships with others might be compromised or that they might have some conflict with their parents [15]. Today, students face many learning challenges and lack of academic motivation; therefore, using educational games can destroy or decrease children's lack of motivation and enthusiasm and improve their learning achievement. Regarding the benefits of motivational games, many educational instructors suggested that games are effective in enhancing student performance because they make students more engaged in the learning process [16]. In recent years, numerous studies have investigated various aspects of our studied variables; Unfortunately, current empirical research conducted on digital game-based learning mainly focuses on adolescents. However, few studies have been conducted to evaluate students' motivation for achievement and stress using computer games. For example, the results of the study by Burden and Byerd [17] have shown that educational games are generally regarded as an effective strategy and promote students' learning and motivation in a classroom.

Acc DLGs (Digital games) can be implemented successfully within schools. It is clear that DLGs are an effective tool. Ording to a study by Acquah and Katz [18]. In another study, Khazaie et al. [19] found that computer educational games increase students' creativity and academic achievement. Pront, Muller, Koschade, and Hutton [20] concluded in their study that: Evaluations of identified games found generally positive results regarding usability and effectiveness of videogames in nursing education. Analysis of advantages of videogames in nursing education identified potential benefits for decision-making, motivation, repeated exposure, logistical, and financial value.

Kebritchi., Hirumi \& Bai [21] concluded in their study that students who played the games in their classrooms and school labs reported greater motivation and achievement compared with those in the control group. In an analysis by Ganotice and Chan [22] Findings suggest that students' achievement (product) in CS-IPTBL is influenced by their motivation, enjoyment, and perceived usefulness (process) which were derived from two sources:individual preparedness and members' valuable contribution (presage). Esmailie Goojar, Ali Abadi, and Roustaei Ardakani [23] concluded that web-based multifunctional computer training games play an effective role in student learning and motivation. Likewise, Ghadirian, Musa Pour, and Akbari [24] 
reported that educational computer games based on the cognitive processes could improve the motivation and academic achievement of students with reading-related problems. In an investigation by Dortaje [25], it was shown that the students who were trained by the instructional game had higher levels of motivation and academic achievement than those students who were trained through the conventional instructional method. Yeh, Chang and Chen [26] concluded that mindful learning is a crucial mediator of mastery experience in digital game-based learning of creativity. With key features of story-based, interdisciplinary, and 3-D design, The DGLC provides an original and valuable vehicle for creativity learning.

The results of the above-mentioned studies support the potentialities of educational computer games for children's teaching. Since most people have access to these games today, so they can be used appropriately to fulfill cognitive and educational goals. These studies used computer games for training the learners, which was the only way to create an interaction between the students and instructors. One of the main differences between this study and the other studies is the placement of two stress and achievement motivation variables and their measurement using computer games. Findings and recommendations of this study would be useful for psychologists, counselors, health care providers, teachers, and education to improve students' interest and enthusiasm for learning, reduce stress, identify stressors, and remove them. According to the above-mentioned descriptions, the general objective of the study is to investigate the impact of computer-based educational games on academic motivation and stress reduction in students.

\section{Method}

This study aimed to investigate the impact of educational computer games on academic motivation and stress reduction in high school students. This study has an applied purpose and used a quasi-experimental pretest-posttest design with control and experimental groups. The study population consisted of all high school students studying in Shiraz high schools in the academic year 2019-20, From the age of 14 to
17 years, who were selected using the convenience sampling technique after matching the pre-test administration of achievement motivation and stress measurement questionnaires. Eighty subjects were selected and assigned to two experimental $(\mathrm{N}=40)$ and control $(\mathrm{N}=40)$ groups. The educational computer games in the market were firstly identified and next, the games, with high adaptation relevant to the research variables, were selected for the study. Then, all participants in both control and experimental groups filled the T. M. A and CISS questionnaires through a pretest administration. The experimental group received an intervention consisting of fifteen training sessions of 45 minutes each for two months and finally, all members of both groups were re-evaluated by post-test administration. Test of Motivation Achievement by Hermans [27] was utilized for measuring the student's achievement motivation level. Having administered the experiment and analyzing the items, as well as computing the correlations between the items with the whole test, 21 modified items were selected to make up the final achievement motivation questionnaire. The questionnaire items were adjusted based on a five-point Likert scale. The reliability of the questionnaire was calculated to be 0.89 using Cronbach's alpha coefficient. The Beck Anxiety Inventory (1988) was used to measure the students' anxiety level. The test consists of 21 items that measure the symptoms of anxiety. It was set based on a fivepoint Likert scale. The reliability of the questionnaire was calculated to be 0.90 using Cronbach's alpha coefficient. In addition, Pearson correlation coefficient was used to calculate the correlation of questionnaire items. The correlation coefficients of problem-oriented coping style, emotion-oriented coping style, and avoidance- oriented coping style were measured $0.58,0.55$ and 0.93 , respectively.

\section{Results}

The descriptive indices of data were divided into three groups: central indices, dispersion indices and indices of distribution shape. This section examines how the research variables are distributed based on the most important central (mean 1) and dispersion (standard deviation 2) indices.

Table 1. Central indices, dispersion and distribution of the variables under study.

\begin{tabular}{|c|c|c|c|c|c|c|}
\hline Variables & & Maximum & Minimum & Standard Deviation & Mean & Number \\
\hline \multirow{3}{*}{ Pre-test motivation } & Control & 2.9 & 1.95 & 30887 & 2.5274 & 40 \\
\hline & Experimental & 4 & 1.81 & 58311 & 2.5464 & 40 \\
\hline & Total & 4 & 1.81 & 46373 & 2.5369 & 80 \\
\hline \multirow{3}{*}{$\begin{array}{l}\text { Post-test } \\
\text { motivation }\end{array}$} & Control & 5 & 1.95 & 66735 & 2.6143 & 40 \\
\hline & Experimental & 5 & 1.95 & 96481 & 3.075 & 40 \\
\hline & Total & 5 & 1.95 & 85623 & 2.8446 & 80 \\
\hline \multirow{2}{*}{ Pre-test stress } & Control & 4.9 & 1.38 & 1.01626 & 2.8131 & 40 \\
\hline & Total & 4.9 & 1.33 & 95150 & 2.7417 & 80 \\
\hline \multirow{3}{*}{ Post-test stress } & Control & 4 & 1.05 & 1.17719 & 2.5238 & 40 \\
\hline & Experimental & 1.71 & 30 & 34277 & 1.2154 & 40 \\
\hline & Total & 4 & 30 & 1.08423 & 1.8696 & 80 \\
\hline
\end{tabular}

According to the results in Table 1, mean, standard deviation, minimum and maximum values for all variables were individually analyzed in both the control and experimental groups. The valid Kolmogorov-Smirnov and 
Shapiro-Wilk tests were used to test the normality assumption of research data. According to the table, if the significance level for all independent and dependent variables is greater than the test level (0.05), the data is normally distributed. In addition, the central limit theorem can be used to measure the normal distribution of the variables. According to the theorem, when the sample size is greater than 30 , the data distribution can be considered normal.

Table 2. Kolmogorov-Smirnov and Shapiro-Wilk tests for the variables.

\begin{tabular}{lllll}
\hline Variables & Kolmogorov - Smirnov test & Significance Level & Shapiro-Wilk test & Significance Level \\
\hline Motivation & 124 & $210^{*}$ & 970 & 508 \\
Stress & 113 & $234^{*}$ & 960 & 274 \\
\hline
\end{tabular}

As shown in Table 2, the significance level of Kolmogorov-Smirnov and Shapiro-Wilk tests for all variables is greater than 0.05. Therefore, we can conclude that these variables are normally distributed and parametric tests can be used to prove the research hypotheses.

Table 3. Levene's test results.

\begin{tabular}{lll}
\hline Variables & Significance Level & Levene's test \\
\hline Motivation & 616 & 257 \\
Stress & 697 & 155 \\
\hline
\end{tabular}

As displayed in the above table, since the significance level for all the variables in the Levene' $\mathrm{s}$ test was calculated to be greater than 0.05 , it can be concluded that the homogeneity of equal variance is confirmed for all research variables.

Hypothesis 1: Educational games have a significant impact on students' academic motivation.

Table 4. Result of covariance analysis.

\begin{tabular}{|c|c|c|c|c|c|}
\hline Source & significance level & $\mathbf{F}$ & Average of squares & Degrees of freedom & Sum of mean squares \\
\hline Modified model & 000 & 19.735 & 9.814 & 2 & $19.627^{\mathrm{a}}$ \\
\hline Pretest motivation & 000 & 30.933 & 15.382 & 1 & 15.382 \\
\hline Group & 006 & 7.875 & 3.916 & 1 & 3.916 \\
\hline Error & & & 497 & 77 & 38.290 \\
\hline Total & & & & 80 & 705.277 \\
\hline Modified model & & & & 79 & 57.917 \\
\hline
\end{tabular}

a. R Squared=.339 (Adjusted R Squared=.332).

According to the above table, since the significance level $(\mathrm{f}=7.875$ ) was calculated to be less than 0.05 , it can be concluded that the educational games have a significant impact on students' academic motivation and the hypothesis is confirmed. It should be noted that the impact level is 33.9.

Hypothesis 2: Educational games have a significant impact on students' stress level.

Table 5. Result of covariance analysis.

\begin{tabular}{llllll}
\hline Source & significance level & F & Average of squares & Degrees of freedom & Sum of the mean squares \\
\hline Modified model & 000 & 23.039 & 17.384 & 2 & $34.768^{\text {a }}$ \\
Pretest stress & 406 & 699 & 528 & 1 & 528 \\
Group & 000 & 45.973 & 34.689 & 7 & 34.689 \\
Error & & & 755 & 77 & 58.100 \\
Total & & & 80 & 372.496 \\
Modified model & & & & 79 & 92.868 \\
\hline
\end{tabular}

a. R Squared=374 (Adjusted R Squared=358).

According to the above table, since the significance level $(\mathrm{f}=45.973$ ) was calculated to be less than 0.05 , it can be concluded that the educational games have a significant impact on students' stress levels and the hypothesis is confirmed. It should be noted that the impact level is 37.4.

\section{Discussion and Conclusion}

Motivation is an internal phenomenon that drives a person from within and arises from the needs of the individual [27]. Motivation plays a very important role in explaining the cause of behavior, predicting the effects of actions and guiding behavior in order to achieve the goal and gives energy to the learner and guides her activities and causes the development of behavior [28]. Studies show that most innovations, productions, discoveries and creativity are the result of high effort and motivation [29] One of the most important issues affecting students' academic achievement is motivation [30] It has been shown that there is a relationship between learning and motivation so that learners' prior knowledge affects their motivation [31]. Computer training creates motivation and motivation in students, which reduces stress in the teachinglearning process and creates peace of mind in students. The use of flexible space and facilities during teaching increases the 
level of motivation. It is possible that computer games have given this opportunity to teachers [32].

This study aimed to investigate the impact of educational computer games on academic motivation and stress level reduction in high school students. The results revealed that educational games are effective in students' stress level and academic motivation. In addition to motivational features, computer-based educational games can play an important role in improving academic achievement and creativity and its constituent components. The designers of these games develop innovative learning opportunities in the form of interesting and non-linear patterns for learners; they are thus allowed to be involved in the implementation and production of learning content by choosing different options in the learning process. Computer games are among the tools that provide students with an objective and engaging environment and make learning entertaining and fun. The new and emerging technologies are capable to facilitate learning, increase their speed, reduce learning time, as well as create more favorable conditions for learning (Yaghmaie, 2011). This type of education develops a desire and motivation for learning in the students resulting in stress reduction in the teaching-learning process and guarantees peace of mind for the students. In addition, use of flexible space and facilities while teaching increases the motivation level; therefore, computer games are likely to provide teachers with the opportunity [32]. The results of our study are consistent with those studies by Ganotice and Chan [22], Khazaiee and Jalilian (2015), Pront et al. [20], Kebritchi \& et al. [21], Goojar et al. [23], Ghadirian et al. [24], Dortaj [25] and Acquah and Katz [18].

\section{Disclosure Statement}

There is no conflict of interest within this study, and the data set sharing is a natural extension of open access, at the request of the authors.

\section{Acknowledgements}

The authors would like to thank all the students and the school teachers for their participation in the didactic intervention. In the reported research, the appropriate procedures were followed according to institutional contexts and ethics. Every student participated in the study voluntarily. Data obtained from the students were fully anonymous, and derived through pre- and post-tests, surveys, and observation. The survey did not contain questions of a personally sensitive nature. The collected data were analysed in an aggregate manner and used exclusively for educational and research purposes.

\section{Copyrights}

Copyright for this article is retained by the author (s), with first publication rights granted to the journal. This is an open- access article distributed under the terms and conditions of the Creative Commons Attribution license.

\section{References}

[1] Atashk, M., Bradaran, B.-M., \& Ahmadvand, A. (2014). Impact of computer educational games on students' social skills and academic achievement. Journal of Educational Technology Research, 4 (7), 297-305. http://jte.sru.ac.ir/article_154.html.

[2] Wilkinson, P. (2016). A brief history of serious games. In Entertainment computing and serious games. Springer, Cham. https://doi.org/10.1007/978-3-319-46152-6_2.

[3] Gullu, H., \& Delialioglu, O. (2018). The Effect of Computer Network Simulators on Students' Motivation and Learning. Journal of Learning and Teaching in Digital Age, 3 (2), 12-21. https://www.learntechlib.org/p/209506/.

[4] Wolf,m.j.p,. \& Perron.B. (2003). The video game theory reader. New York: Rout ledge press.

[5] Sutton-Smith, B. (2004). Video conference with Brian SuttonSmith and Eric Zimmerman. Presented at the Digital Games Research Association (DIGRA), Level Up International Conference. Utrecht, The Netherlands.

[6] Yaghma, A. (2011). Teacher in National Curriculum. Journal of Educational Technology Growth, 26 (1), 2-3. https://www.roshdmag.ir/fa/article.

[7] Khan, A., \& Madden, J. (2018). Active learning: a new assessment model that boost confidence and learning while reducing test anxiety. International Journal of Modern Education and Computer Science, 10 (12), 1.

[8] Mohr, W. K., Petti, T. A., \& Mohr, B. D. (2003). Adverse effects associated with physical restraint. The Canadian Journal of Psychiatry, 48 (5), 330-337. https://doi.org/10.1177/070674370304800509.

[9] Ashraf Jahanian, A. (2012). The Relationship between thinking styles and stress with its strategies (Unpublished M. Sc. thesis) . Islamic Azad University, Central Tehran Branch, Faculty of Psychology and Social Sciences, Iran.

[10] Shakeri, R. (2016). Investigating the relationship between religious orientation and academic achievement motivation with the mediating resilience in students of Ferdowsi University of Mashhad (Unpublished M. Sc. thesis (. Ferdowsi University of Mashhad, Faculty of Psychology and Educational Sciences, Iran.

[11] Pintrich, Paul R., Conley, Anne Marie M. \& Kempler, Toni M. (2003). Current issues in achievement goal theory and research. International Journal of Educational.

[12] Clark, M. H., \& Schroth, C. A. (2010). Examining relationships between academic motivation and personality among college students. Journal of Learning and Individual Differences, 20, 19-24. https://eric.ed.gov/?id=EJ866899.

[13] Ejehie, J. S., Visani, M. S., \& Siadat (2011). Academic motivation and statistics anxiety, investigating the mediating role of learning strategies. Journal of Psychology, 15 (2), 110128. http://noo.rs/T9u4Y. 
[14] Toyserkani Ravari, F., Arabzadeh, M., \& Kadivar, P. (2016). The Relationship between classroom environment, development goals, and reflective thinking with students' mathematical performance. School Psychology Journal, 4 (1), 52-69. https://www.sid.ir/En/Journal/ViewPaper.aspx?ID=538858.

[15] Shaari Nejad, Ali Akbar, (2008), Philosophy of Education. Tehran, Amir Kabir Publications. ISBN: 978-964-00-0123-3.

[16] Kulik, C. L. C. (1984). Effects of computer-based education on elementary school pupils.Khan, A., \& Madden, J. (2018). Active learning: a new assessment model that boost confidence and learning while reducing test anxiety. International Journal of Modern Education and Computer Science, 10 (12), 1. doi: 10.5815/ijmecs.2018.12.01.

[17] Burden, P. R., \& Byrd, D. M. (1999). Methods for effective teaching.

https://catalogue.pearsoned.co.uk/assets/hip/gb/hip_gb_pearso nhighered/preface/0134695747.pdf.

[18] Acquah, E. O., \& Katz, H. T. (2020). Digital game-based L2 learning outcomes for primary through high-school students: A systematic literature review. Computers \& Education, 143, 103667. doi: 10.1016/j.compedu.2019.103667.

[19] Khazaei, K., \& Jalilian, N. (2014). The Impact of computer educational games on academic achievement and creativity in elementary school students. Journal of Information and Communication Technology in Psychology and Educational Sciences, 5 (2), 23-39. http://noo.rs/ozUOT.

[20] Pront, L., Muller, A., Koschade, A., \& Hutton, A. (2018). Gaming in nursing education: a literature review. Nursing education perspectives, 39 (1), 23-28. doi: 10.1097/01.NEP.0000000000000251.

[21] Kebritchi, M., Hirumi, A., \& Bai, H. (2010). The effects of modern mathematics computer games on mathematics achievement and class motivation. Computers \& education, 55 (2), 427-443. doi: 10.1016/j.compedu.2010.02.007.

[22] Ganotice Jr, F. A., \& Chan, L. K. (2019). How can students succeed in computer-supported interprofessional team-based learning? Understanding the underlying psychological pathways using Biggs' $3 \mathrm{P}$ model. Computers in Human Behavior, 91, 211-219. doi: 10.1016/j.chb.2018.09.029.

[23] Esmailie Goojar, S., Ali Abadi, Kh., \& Roustaei Ardakani, S. (2018). Impact of web-based multi-user educational computer games on student learning and motivation. Journal of Media Studies in Vienna, 3 (11), 196-223.
https://www.civilica.com/Paper-JR NMS-JR NMS-311_007.html.

[24] Ghadirian, S., Musa Pour, S., \& Akbari, S. (2018). The effect of cognitive process-based educational games on academic motivation and academic achievement of students with reading difficulties. Journal of Learning Disabilities, 7 (1), 76-99. https://www.sid.ir/en/Journal/ViewPaper.aspx?ID=577086.

[25] Dortaj, F. (2014). Comparing the effect of two-game and traditional teaching methods on students' motivation and academic achievement in mathematics. Journal of School $\begin{array}{llll}\text { Psychology, } & 2 & \text { (4), }\end{array}$ https://www.sid.ir/En/Journal/ViewPaper.aspx?ID=489925.

[26] Yeh, Y. C., Chang, H. L., \& Chen, S. Y. (2019). Mindful learning: A mediator of mastery experience during digital creativity game-based learning among elementary school students. Computers \& Education, 132, 63-75. doi: 10.1016/j.compedu.2019.01.001.

[27] Rouhi G, Hoseini SA, Badeleh MT, Rahmani H.[Educational Motivation and its Relationship with some Factors among the Students of Golestan University of Medical Sciences]. Strides In Development of Medical Education 2007; 4 (2): 77-83.

[28] Kosgeroglu N, Acat MB, Ayranci U, Ozabaci N, Erkal S. An investigation on nursing, midwifery and health care students' learning motivation in Turkey. Nurse Educ Pract 2009; 9 (5): $331-9$.

[29] Abbas pour S, Hasan zedeh M. [Motivations for the choice of the nursing course in faculty of nursing in Torbat Heidaryeh]. Journal of Urmia Nursing And Midwifery Faculty 2008; 6 (2): $71-4$.

[30] Amini A, Valizadeh S, Mohammadi B. [Survey of effective factors on learning motivation of clinical students and suggesting the appropriate methods for reinforcement the learning motivation from the viewpoints of nursing and midwifery faculty, Tabriz University of Medical Sciences 2002]. Iranian Journal of Medical Education 2002; 2 (0): 1011 .

[31] Bengtsson M, Ohlsson B. The nursing and medical students motivation to attain knowledge. Nurse Educ Today 2010; 30 (2): $150-6$.

Sobke, H., \& Reichelt, M. (2018). Sewer Rats in Teaching Action: An explorative field study on students' perception of a game-based learning app in graduate engineering education. arXiv preprint arXiv: 1811.09776. https://arxiv.org/abs/1811.09776. 